\title{
Modal determiners and alternatives: Quantity and ignorance effects *
}

\author{
Luis Alonso-Ovalle \\ McGill University
}

\author{
Paula Menéndez-Benito \\ University of Göttingen
}

\begin{abstract}
The literature on epistemic indefinites has explored the possibility that different pragmatic competitors give rise to different epistemic effects (AlonsoOvalle \& Menéndez-Benito 2010; Fălăuş 2009). Like epistemic indefinites, "class B modified numerals" (Nouwen 2010), such as English at least $n$, signal speaker ignorance. This paper examines the modal component of the Spanish complex determiner algún que otro, which, like at least $n$, conveys that the speaker does not know how many individuals satisfy the existential claim. We show that the modal components of at least $n$ and algún que otro differ. Unlike at least $n$, algún que otro does not determine the minimum number of individuals that, according to the speaker, might satisfy the existential claim. We argue that the epistemic component of algún que otro is an implicature, and, building on the discussion in Nouwen (forthcoming), we contend that the contrast between at least $n$ and algún que otro can also be traced back to the different pragmatic competitors that these items invoke.
\end{abstract}

Keywords: Modal determiners, alternatives, implicatures.

\section{Introduction}

Cross-linguistically, we find existential expressions that can signal ignorance on the part of the speaker. Two types of items that belong to this category are epistemic indefinite determiners, like Spanish algún or English singular some, ${ }^{1}$ and "class B

* The names of the authors are listed in alphabetical order. We would like to thank the audiences of SALT 23 and the 19 International Congress of Linguists in Geneva for useful feedback. Thanks also to Rick Nouwen, for helpful exchanges on his most recent work on at least $n$. One of the authors is grateful to Monsieur Pinchot for feeding in much rich input. The research presented here has received financial support from the Social Sciences and Humanities Research Council of Canada (Insight Grant 435-2013-0103, Luis Alonso-Ovalle, principal investigator; Bernhard Schwarz and Junko Shimoyama, co-applicants) and the Fonds de Recherche Societé et Culture du Québec (Établissement de nouveaux professeurs-chercheurs program grant 2013-NP-164823, Luis Alonso-Ovalle, principal investigator; and Soutien aux équipes de recherche program grant 2012-SE-144646, Lisa Travis, principal investigator).

1 See Alonso-Ovalle \& Menéndez-Benito 2013 for discussion of two recent accounts of epistemic indefinites and for recent references on the topic. 
Modal determiners and alternatives

modified numerals" (Nouwen 2010), like English at least $n$.

Consider, for instance, the Spanish sentence in (1), with the epistemic indefinite algún. This sentence makes an existential claim (that Juan is in a room of the house) and additionally signals that the speaker does not know which room Juan is in. Hence, a continuation that explicitly identifies the room in question is infelicitous, as (2) shows.

(1) Juan está en alguna habitación de la casa.

Juan is in ALGUNA room of the house

'Juan is in some room or other of the house.'

(2) Juan está en alguna habitación de la casa. \# En concreto, en el

Juan is in ALGUNA room of the house namely in the

baño.

restroom

'Juan is in some room of the house or other. Namely in the restroom.'

Similarly, the sentence in (3), with English at least two, conveys that Juan bought a number of books (two or more), and that the speaker does not know exactly how many. As a result, it is odd to specify the exact number of books that Juan bought, as (4) illustrates.

(3) Juan bought at least two books.

(4) Juan bought at least two books. \# To be precise, three.

Both of these ignorance components have been analyzed as quantity implicatures. ${ }^{2}$ In previous work (Alonso-Ovalle \& Menéndez-Benito 2008, 2010, 2011) we have explored the possibility that different epistemic indefinites trigger different types of pragmatic competitors, which may give rise to different epistemic effects (see also Fălăuş 2009). In this paper, we present a novel contrast in the domain of 'don't know how many' effects, and argue that this contrast can also be traced back to the type of pragmatic competitors.

This paper examines the ignorance effect of the Spanish complex determiner algún que otro, and compares it to that of at least $n$. Like at least $n$, algún que otro makes an existential claim and signals that the speaker does not know how many individuals satisfy this claim. For instance, the sentence in (5) conveys that Juan bought a number of books and that the speaker does not know exactly how many (hence, the oddity of the continuation).

2 The ignorance effect of epistemic indefinites has been treated as a quantity implicature by AlonsoOvalle \& Menéndez-Benito (2008, 2010) (building on Kratzer \& Shimoyama 2002), and Fălăuş 2009, among others. For implicature-based analyses of at least $n$, see Büring 2008, Cummins \& Katsos 2010, Schwarz 2013 and Cohen \& Krifka 2011, among others. 
Despite the apparent parallelism between at least $n$ and algún que otro, we show that these two items differ: only the former triggers a 'lower bound component.' The sentence in (3) says that the smallest number of books that Juan might have bought, according to the speaker, is five. In contrast, (5) says nothing about the smallest number of books that the speaker thinks Juan might have bought. Building on work by Nouwen (forthcoming) on at least $n$, we argue that this difference can be derived by assuming that the two items evoke different pragmatic alternatives.

The paper is organized as follows: Section 2 discusses the contrast between at least $n$ and algún que otro in more detail. Section 3 summarizes the implicaturebased account of at least $n$ put forth in Büring 2008, argues that the ignorance effect of algún que otro is an implicature, and presents a derivation of this implicature following the discussion of at least $n$ in Nouwen forthcoming. Section 4 discusses cases with deontic modals. Finally, section 5 briefly concludes.

\section{Algún que otro vs. at least n: The lower bound contrast}

As is well known, a sentence like (6) below conveys that, as far as the speaker knows, Juan might have bought exactly two books and he might have bought more than two (see, for instance, Geurts \& Nouwen 2007 and Büring 2008). Thus, (6) tells us that the smallest number of books that, according to the speaker, Juan might have bought (what we will call 'the epistemic lower bound') is two.

(6) Juan bought at least two books.

Because of this epistemic lower bound, the discourse in (7) is deviant. The first sentence commits the speaker to the possibility that Juan might have bought exactly two books, while the second rules out this possibility.

(7) Juan bought at least two books. \# Definitely no fewer than three.

Let us consider now the counterpart of (6) with the complex Spanish determiner algún que otro:

(8) Juan compró algún que otro libro.

Juan bought ALGÚN QUE OTRO book

'Juan bought books.' 
Modal determiners and alternatives

Although algún que otro is morphologically singular, the sentence in (8) conveys, like the one in (6), that Juan bought a plurality of books. ${ }^{3}$ In that, algún que otro behaves like the plural indefinites algunos and unos cuantos, in (9) below. ${ }^{4}$

a. Juan compró algunos libros. Juan bought ALGUNOS books

'Juan bought some books.'

b. Juan compró unos cuantos libros.

Juan bought UNOS CUANTOS books

'Juan bought a few books.'

As noted above, algún que otro signals that the speaker does not know how many books Juan bought. In this respect, algún que otro differs from the plural indefinites in (9), as illustrated below.

a. Juan compró algún que otro libro. \# En concreto tres.

Juan bought ALGÚN QUE OTRO book. to be concrete three

b. Juan compró algunos libros. En concreto tres.

Juan bought ALGUNOS books. to be concrete three

'Juan bough some books. Three, to be exact.'

c. Juan compró unos cuantos libros. En concreto tres.

Juan bought UNOS CUANTOS books. to be concrete three

'Juan bough a few books. Three, to be exact.'

While algún que otro patterns with at least $n$ in conveying an epistemic effect, these items differ in that algún que otro does not convey information about the speaker's epistemic lower bound. The sentence in (8) is compatible with situations where the speaker believes that Juan bought three or more books, four or more books, five or more books, etc. As a consequence, the discourse in (11) is felicitous.

(11) Juan compró algún que otro libro. Seguro que no menos de tres / Juan bought ALGÚN QUE OTRO book sure that no fewer than three / cuatro / cinco ...

four / five

'Juan bought books. Definitely no less than three / four / five ...'

3 We translate algún que otro with an English bare plural, but we do not want to commit to an equivalence between these two types of expressions. Notice that algún is also morphologically singular but semantically number neutral (Alonso-Ovalle \& Menéndez-Benito 2010).

4 See Gutiérrez-Rexach 2010 and references therein for an overview of Spanish indefinites. Like the indefinites in (9), algún que otro conveys that the number of books that Juan bought is not large, an upper bound component that we will ignore for the rest of the paper, since it is arguably orthogonal to the point that we make below. 
The dialogue in (12) below illustrates this point further:
a. L: ¿Cuántos hijos tiene Juan? how many children has Juan 'How many children does Juan have?'
b. P: Al menos dos. at the least two
'At least two.'
c. P: \# Alguno que otro.
ALGUNO QUE OTRO

The answer in (12b), with the Spanish counterpart of at least two (al menos dos), is a partial answer to the question in (12a), but it still gives us some information about P's epistemic state. From (12b), we can conclude that $\mathrm{P}$ considers two as a live possibility. In contrast, the answer in (12c) contributes no information about the epistemic state of the speaker, other than the fact that she knows that Juan has children - (12c) is compatible with a variety of scenarios, including scenarios where the speaker thinks that Juan has two kids or more, scenarios where she thinks that Juan has three kids or more, four kids or more, etc. As a result, this answer is deviant.

In the next section we will show that this contrast between algún que otro and at least $n$ can be derived by assuming that the two items trigger different types of pragmatic competitors. Section 3.1 presents Büring's account of the ignorance effect of at least $n$ as an implicature (Büring 2008). Section 3.2 shows that the ignorance effect of algún que otro is also an implicature, and - building on the discussion of at least $n$ in Nouwen forthcoming - puts forward a derivation of this implicature that crucially differs from Büring's in the types of alternatives considered. Section 3.3 extends this proposal to cases where algún que otro is under a deontic modal.

\section{The epistemic effects as implicatures, and their derivations}

\subsection{The modal effect of at least $n$ as an implicature: Büring (2008).}

Büring (2008) analyzes at least $n$ as the corresponding disjunction $n$ or more. On this view, the sentence in (6), repeated below as (13a), asserts (13b).

(13) a. Juan bought at least two books.

b. Juan bought exactly two books or he bought more than two books.

Following Sauerland (2004), let us assume that the set of pragmatic competitors to a disjunctive sentence of the form ${ }^{\ulcorner} A$ or $\left.B\right\urcorner$ includes its conjunctive counterpart 
${ }^{\ulcorner} A$ and $\left.B\right\urcorner$ and the atomic disjuncts $A$ and $B$. The sentence in (13a) invokes then the two competitors in (14) below. As these two competitors are mutually incompatible, the conjunctive competitor would be a contradiction, and can therefore be excluded.

a. Juan bought exactly two books.

b. Juan bought more than two books.

The competition between (13b) and (14) yields the primary implicatures in (15) below (where ' $\square$ ' quantifies over the worlds compatible with the speaker's beliefs). That is, the speaker is not convinced that Juan bought exactly two books, and she is not convinced that Juan bought more than two books. Note that strengthening the implicatures further is not possible. By the Maxim of Quality, we can assume that the speaker believes that the proposition in (13b) is true (as in (16)). The secondary implicatures in (17) would contradict that assumption.

a. $\neg \square$ Juan bought exactly two books.

b. $\neg \square$ Juan bought more than two books.

(16) $\square$ (Juan bought exactly two books or he bought more than two books).

(17) a. $\square \neg$ (Juan bought exactly two books).

b. $\square \neg$ (Juan bought more than two books).

Putting (16) together with the two implicatures in (15) entails that the speaker considers it possible that Juan bought two books, and also that he bought more than two. Therefore, (13a) gives us information about the speaker's epistemic lower bound: the smallest $n$ such that (13a) conveys that the speaker believes Juan might have bought (exactly) $n$ books.

We turn next to the ignorance effect triggered by algún que otro. In section 3.2 we argue that this effect is a quantity implicature and in section 3.3 we put forward a derivation of this implicature.

\subsection{The modal effect of algún que otro is an implicature}

The epistemic effect of algún que otro patterns with (quantity) implicatures in two respects. First, as (18) illustrates, conversational implicatures can be reinforced without redundancy (see (18a)), unlike entailments, as in (18b), presuppositions, as in (18c), or conventional implicatures, as in (18d). The epistemic effect of algún que otro can also be reinforced without redundancy, as the discourse in (19) illustrates. 
(18) a. Pinchot ate some of the cookies, but not all.

b. \# Pinchot is a Canadian baker, and he is a baker.

c. \# The king of France is bald, and France has a king.

d. \# Pinchot, a baker from Canada, won a prize, and he is Canadian.

(19) Juan compró algún que otro libro, pero no sé cuántos.

Juan bought ALGÚN QUE OTRO book but not I-know how-many.

'Juan bought books but I don't know how many.'

Second, quantity implicatures disappear in downward entailing contexts (Gazdar 1979; Horn 1989): the sentence in (20a) can be used to convey that Juan didn't eat any cookies, and the sentence in (20b) quantifies over all the students that read books in the reading list (including those who read all the books). The epistemic effect of algún que otro also disappears in downward entailing contexts: the sentence in (21) can be uttered by a speaker who knows perfectly well how many books each professor bought. The sentence simply conveys that all the professors that bought books presented a receipt. ${ }^{5}$

(20) a. It is not true that John ate some cookies.

b. All the students who read some books in the reading list will pass the course.

(21) Todos los profesores que compraron algún que otro libro presentaron all the professors that bought ALGÚN QUE OTRO book presented un recibo.

a receipt

'All the professors that bought books presented a receipt.'

If the ignorance effect of algún que otro is an implicature, how does it come about? We turn next to this issue.

\subsection{Derivation of the implicature}

Recent work on at least $n$ (Schwarz 2013, Nouwen forthcoming) critically explores the possibility of deriving the modal component of this item as an implicature,

5 The behavior of algún que otro in downward entailing contexts deserves further investigation. While the example in (21) is fine, at least to our ear, algún que otro is odd in some downward entailing contexts, like the one below.

(i) Juan raramente compra algún que otro libro. Juan rarely buys ALGÚN QUE OTRO book

In this connection, note that Nilsen (2007) observes that superlative quantifiers like at least $n$ are bad in many downward entailing contexts. See Cohen \& Krifka 2011 for discussion. 
without having to stipulate, as Büring does, that at least $n$ is formally equivalent to the disjuction $n$ or more. These discussions investigate the effect of assuming that $a t$ least $n$ triggers a pragmatic competition both with exactly $n$, exactly $n+1, \ldots$ (the exactly-competitors), and with at least $n+1$, at least $n+2, \ldots$ (the scalar competitors). Nouwen (forthcoming) motivates the exactly-competitors by applying to at least $n$ the account of the Spanish epistemic indefinite algún in Alonso-Ovalle \& MenéndezBenito (2010). In our analysis of algún que otro, we adopt this part of Nouwen's proposal, and contend that this item competes only with these exactly-competitors. In the next section, we briefly summarise our proposal for algún.

\subsubsection{Alonso-Ovalle \& Menéndez-Benito (2010) on algún}

As noted in the introduction, algún triggers an ignorance effect — that the speaker cannot identify the witness of the existential claim. For instance, the sentence in (22) conveys that the speaker does not know what room Juan is in.

(22) Juan está en alguna habitación de la casa.

Juan is in ALGUNA room of the house

'Juan is in some room or other of the house.'

The epistemic effect of algún patterns with quantity implicatures in that it can be reinforced without redundancy, as in (23a), and it disappears in downward entailing contexts, as in (23b) (Alonso-Ovalle \& Menéndez-Benito 2010).

a. Juan está en alguna habitación de la casa pero no sé en cuál. Juan is in ALGUNA room of the house, but not I-know in which 'Juan is in some room of the house but I don't know which.'

b. No es verdad que Juan esté en alguna habitación de la casa. Not is true that Juan is in ALGUNA room of the house 'Juan is not in any room of the house.'

Building on the analysis of German irgendein presented in Kratzer \& Shimoyama 2002, we proposed in Alonso-Ovalle \& Menéndez-Benito 2008 and Alonso-Ovalle \& Menéndez-Benito 2010 that the ignorance implicature triggered by algún arises because this item signals that its domain of quantification cannot be a singleton set.

To implement this idea, we modelled domain restrictions via subset selection functions. Subset selection functions take a set and return one of its subsets. Contextual domain restrictions can be captured by assuming that quantifiers combine with a subset selection function $f$ that selects a subset from the denotation of the noun phrase (von Fintel 2000; Kratzer 2003; Kratzer 2005). Particular lexical items can impose conditions on this function. In our analysis, algún requires its subset 
selection function to be an 'anti-singleton' selection function, a function that always returns a non-singleton subset of its argument. Our proposed denotation for algún is in (24).

$$
\llbracket \text { algún } \rrbracket=\lambda f: \text { anti-singleton }(f) \cdot \lambda P \cdot \lambda Q \cdot f(P) \cap Q \neq \varnothing
$$

The anti-singleton constraint imposed by algún is assumed to trigger a competition between the actual assertion and the alternative assertions that would have resulted from restricting the domain to a singleton set. Suppose that the rooms under consideration are the bedroom, the living room, and the bathroom. Given this, the sentence in (22) will correspond to (25), where Be is shorthand for 'bedroom', $L$ for 'living room' and $B a$, for 'bathroom' . ${ }^{6,7}$ Due to the anti-singleton constraint, the assertion competes with the stronger alternatives in (26). Thus, upon hearing (22), we will draw the primary implicatures in (27) (as before, the secondary implicatures would contradict the assumption that the speaker believes her assertion is true (see (28)). The strengthened meaning of (22) then entails that the speaker does not know what room Juan is in.

(25) Juan is in a room in $f(\{\mathrm{Be}, \mathrm{L}, \mathrm{Ba}\})$

(26) a. Juan is in a room in $\{\mathrm{Be}\}$

b. Juan is in a room in $\{\mathrm{L}\}$

c. Juan is in a room in $\{\mathrm{Ba}\}$

a. $\neg \square$ Juan is a room in $\{\mathrm{Be}\}$

b. $\neg \square$ Juan is a room in $\{L\}$

c. $\neg \square$ Juan is a room in $\{\mathrm{Ba}\}$

$\square(\mathrm{Juan}$ is in a room in $f(\{\mathrm{Be}, \mathrm{L}, \mathrm{Ba}\}))$

The next section extends this analysis to algún que otro, following Nouwen forthcoming, who discusses extending it to at least $n$.

6 The assertion made will actually depend on the value of $f$. Given that there are four possible mappings from $\{\mathrm{Be}, \mathrm{L}, \mathrm{Ba}\}$ to one of its subsets with cardinality two or higher, there are four possible asserted propositions, each of which will compete with the singleton alternatives. See Alonso-Ovalle \& Menéndez-Benito 2011 for discussion of this issue.

7 Alonso-Ovalle \& Menéndez-Benito 2008, 2010 assume that sentences like (22) involve a covert epistemic operator. Here, we are assuming that epistemic modality comes in via the Maxim of Quality, a modification that was suggested to us by an anonymous Journal of Semantics reviewer. The two formulations do not make exactly the same predictions. However, the (simpler) derivation above is enough to illustrate the gist of the proposal, and allows for a more direct comparison with existing accounts of modified numerals. 
Modal determiners and alternatives

\subsubsection{Algún que otro as an antisingleton quantifier}

Let us assume that, like algún, algún que otro combines with a subset selection function $f$ and two properties, $P$ and $Q$, and that its meaning is only defined if $f$ is an anti-singleton function. Unlike algún, however, algún que otro does not range over individuals, but over cardinalities. When defined, it gives us truth only if there is a number $n$ in the domain selected by $f$ from a set containing cardinalities two and higher and there are exactly $n$ individuals that are both $P$ and $Q .{ }^{8}$

$$
\begin{aligned}
& \llbracket \text { algún que otro } \rrbracket= \\
& \lambda f: \text { anti-singleton }(f) . \lambda P . \lambda Q . \exists n\left[n \in f\left(\left\{n^{\prime}: n^{\prime} \geq 2\right\}\right) \&|P \cap Q|=n\right]
\end{aligned}
$$

Under this analysis, the sentence in (30) will correspond to (31). As before, the anti-singleton constraint triggers a competition with the propositions obtained by restricting the domain to a singleton, in (32). This competition yields the implicature that the speaker cannot commit to any of the alternatives in (32) (i.e., (33)) and that, therefore, she does not know the exact number of books that Juan bought - the ignorance effect.

(30) Juan compró algún que otro libro.

Juan bought ALGÚN QUE OTRO book

'Juan bought books.'

(31) $\exists n\left[n \in f\left(\left\{n^{\prime}: n^{\prime} \geq 2\right\}\right) \&\right.$ Juan bought exactly $n$ books $]$

(32) a. Juan bought exactly $n$ books $\& n \in\{2\}$.

b. Juan bought exactly $n$ books \& $n \in\{3\}$.

c. Juan bought exactly $n$ books \& $n \in\{4\}$.

d.

(33) a. $\neg \square$ Juan bought exactly 2 books.

b. $\neg \square$ Juan bought exactly 3 books.

c. $\neg \square$ Juan bought exactly 4 books.

d.

Unlike in the case of at least $n$, however, the strengthened meaning does not entail that the speaker believes that Juan might have bought exactly two books. The implicature that we derive is compatible with models where the speaker thinks that Juan might have bought two or more books, as in (34a), three or more books,

8 As noted above, Nouwen (forthcoming) considers the possibility that at least $n$ has this denotation, but he notes that we would need to assume that this item has scalar implicatures on top of the singleton ones. See also Schwarz 2013 for the role of the scalar competitors of at least $n$. 
as in (34b), etc. (and also with models like (34c), where only some cardinalities are possible). ${ }^{9}$ As a result, we don't derive an epistemic lower bound effect. The only requirement that the implicature imposes is that the number of books that Juan bought vary across the epistemic alternatives of the speaker. The range of variation is left open.
a. $w_{0}\left\{\begin{array}{c}w_{1}: \text { Juan bought exactly } 2 \text { books. } \\ w_{2}: \text { Juan bought exactly } 3 \text { books. } \\ w_{3} \text { : Juan bought exactly } 4 \text { books. } \\ \vdots \quad \vdots \quad \vdots\end{array}\right.$
b. $w_{0} \longleftrightarrow \begin{gathered}w_{1}: \text { Juan bought exactly } 3 \text { books. } \\ w_{2}: \text { Juan bought exactly } 4 \text { books. } \\ w_{3} \text { : Juan bought exactly } 5 \text { books. } \\ \vdots \quad \vdots \quad \vdots \quad \vdots\end{gathered}$
c. $w_{0} \longleftrightarrow \begin{aligned} & w_{1}: \text { Juan bought exactly } 6 \text { books. } \\ & w_{2} \text { : Juan bought exactly } 8 \text { books. } \\ & w_{3} \text { : Juan bought exactly } 12 \text { books. }\end{aligned}$

In what follows, we will discuss the behavior of at least $n$ and algún que otro under deontic modals. In section 4.1 we show how a Büring-style account explains the behavior of at least $n$ under deontic necessity modals. In section 4.2 we discuss algún que otro in deontic necessity sentences, and show that the proposal presented in this section can account straightforwardly for these cases. In section 4.3 we deal with the behavior of algún que otro in possibility sentences, and argue that these cases can be accounted for by a different reasoning - 'anti-exhaustivity' (Kratzer \& Shimoyama 2002).

\section{Deontic modals}

\subsection{At least $n$ under deontic necessity modals: the authoritative reading}

Büring (2008) observes that the sentence in (35), where at least $n$ appears under the surface scope of must, has two readings. Under its ignorance reading, the sentence conveys that the password is required to be a specific number of characters, but that the speaker does not know how many: as far as she knows, this number might be five

9 In the pictures in (34), $w_{0}$ is the actual world and worlds $w_{1}, w_{2}, w_{3} \ldots$ represent types of worlds epistemically accessible from $w_{0}$ for the speaker. 
(this is the 'epistemic lower bound', in our terms), or it might be higher. Under its 'authoritative reading', the sentence conveys that the password can have exactly five characters (a 'permitted lower bound') and that it can have more than five characters.

(35) The password must be at least 5 characters long.

(Büring 2008)

In a Büring-style account, we can derive the authoritative reading as follows. ${ }^{10}$ Let us assume that (35) asserts (36a). This assertion will compete with (36b) and (36c) (' $\square$ ' abbreviates 'it is required that.'), which will yield the primary implicatures in (37). In the previous cases, these implicatures could not be strengthened to their corresponding secondary versions and remain consistent with the assertion. In this case, however, the secondary implicatures in (38) are compatible with the assertion. On the assumption that the speaker is well-informed, we can then derive the implicatures in (39). Putting this together with the assertion, we get that the password can be exactly five characters long, and that it also can be longer.

a. $\odot$ (The pasword is exactly 5 characters or it is more than 5 characters).

b. $\odot$ The password is exactly 5 characters.

c. $\odot$ The password is more than 5 characters.

(37) a. The speaker is not convinced that: $₫$ (the password is exactly 5 characters).

b. The speaker is not convinced that: $\bullet$ (the password is more than 5 characters).

(38) a. The speaker is convinced that not: $\odot$ (the password is exactly 5 characters).

b. The speaker is convinced that not: $\bullet$ (the password is more than 5 characters).

(39) a. The password is not required to be exactly 5 characters.

b. The password is not required to be more than 5 characters.

\subsection{Algún que otro under deontic necessity modals}

Algún que otro contrasts with at least $n$ when embedded under deontic necessity modals. The sentence in (40), for instance, is deviant as an instruction. Intuitively, all this sentence conveys is the (trivial) information that the password must have characters. This is expected under the proposal above, which predicts that (40) will not give us information about what the permitted lower bound is.

(40) \# La contraseña debe tener algún que otro carácter. the password must have ALGÚN QUE OTRO character

'The password must have characters.'

10 See Schwarz 2011 for discussion. 
Let us illustrate how this works. The sentence in (40) will make the assertion in (41), which will compete with the propositions in (42). As in section 4.1 above, we can ultimately derive the implicature that all these competitors are false.

$\bullet \exists n\left[n \in f\left(\left\{n^{\prime}: n^{\prime} \geq 2\right\}\right) \&\right.$ the password is exactly $n$ characters $]$
a. $\odot \exists n[n \in\{2\} \&$ the password is exactly $n$ characters $]$
b. $\odot \exists n[n \in\{3\} \&$ the password is exactly $n$ characters $]$
c.

The resulting strengthened meaning rules out models where the password has to be a specific number of characters, but it is still compatible with a wide array of models that vary with respect to the permitted lower bound. The strengthened meaning is satisfied in models like (43a), where the password can have exactly two characters, but also in models where the permitted lower bound is higher, like (43b). ${ }^{11}$ Thus, upon hearing (40), we will not know what model we are in, and therefore will not know what the allowed range of characters is. As a result, (40) is correctly predicted to be deviant.

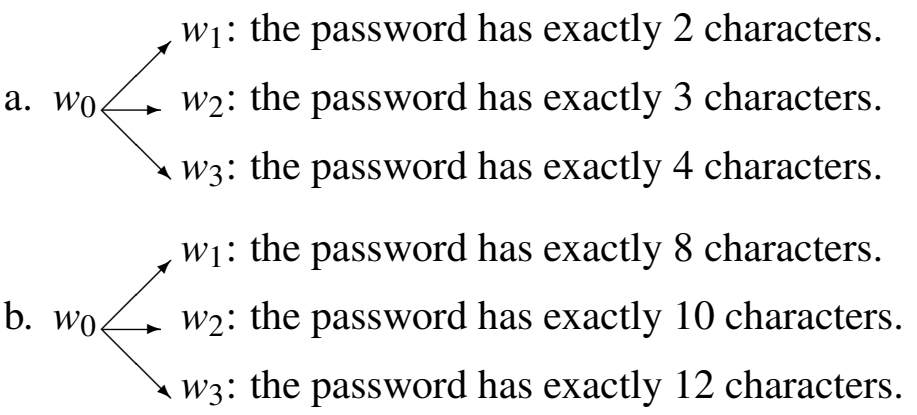

In general, algún que otro and at least $n$ contrast sharply in contexts where determining a permitted lower bound is relevant. Consider, for instance, a course syllabus that states (44) below. When reading (44), students will conclude that the minimum number of pages that they have to write is ten. This is relevant information for those students looking forward to doing the minimum to pass the course. In contrast, (45) says nothing about the minimum number of pages. All the students can conclude from this is that the paper must have pages.

(44) The term paper must have at least ten pages.

(45) El trabajo debe tener alguna que otra página. the paper must have ALGUNA QUE OTRA page

'The paper must have pages.'

11 In the pictures in (43), $\mathrm{w}_{0}$ is the actual world, and $w_{1-3}$ are types of permitted worlds. 
Modal determiners and alternatives

\subsection{Possibility modals}

The proposal above does not yield the right interpretation for possibility modals with algún que otro. ${ }^{12}$ Let us illustrate this with (46) below.

(46) Para relajarte, puedes leer alguna que otra novela policiaca.

To relax, you can read ALGUNA QUE OTRA novel detective

'To relax, you can read detective novels.'

This sentence can convey that, to relax, the addressee can read detective novels, but does not have to read any specific number. However, as things stand, we derive a weaker meaning. The assertion in (47) will compete with the propositions in (48) (' $\odot$ ' abbreviates 'it is possible that'). The primary implicatures yield only the weak inference that the speaker is not convinced about the truth of any of these competitors. Strengthening this implicature further would contradict the assertion.

$\diamond \exists n[n \in f(\{n: n \geq 2\}) \&$ you read exactly $n$ novels $]$
a. $\odot$ [you read exactly $n$ novels $\& n \in\{2\}$ ]
b. $\odot$ [you read exactly $n$ novels $\& n \in\{3\}]$
c.

Exactly the same issue arises with algún in possibility sentences. Alonso-Ovalle \& Menéndez-Benito (2010) follow Kratzer \& Shimoyama (2002) in assuming a different pragmatic reasoning for these cases: anti-exhaustivity. The idea is that the speaker can use an anti-singleton indefinite to prevent the hearer from drawing a potential exhaustivity inference. Suppose that A asks where Juan is, and B replies with (49). B's answer is naturally understood as an exhaustive enumeration of the possible places where Juan might be (Zimmerman 2000). Using a singleton indefinite could trigger the same kind of inference: (50) would indicate that Juan can only be in the kitchen. Following Kratzer \& Shimoyama (2002), Alonso-Ovalle $\&$ Menéndez-Benito (2010) propose that an anti-singleton indefinite can be used to avoid that potential inference.

(49) Juan might be in the bathroom or in the kitchen.

(50) Juan might be in a room in $\{$ kitchen $\}$

Applying this reasoning to our example in (46) yields the desired result. Let us assume, for the sake of illustration, that the only relevant quantities are two, three, and four. Then, anti-exhaustivity will yield the implicatures in (51). These implicatures rule out models where the addressee has to read a particular number of novels, but does not require all quantities to be possibilities.

12 At least $n$ is deviant under possibility modals. See Büring 2008 for discussion. 
a. $\diamond$ you read exactly 2 novels $\rightarrow(\diamond$ (you read exactly 3 novels $) \vee \diamond($ you read exactly 4 novels))

b. $\odot$ you read exactly 3 novels $\rightarrow(\diamond$ (you read exactly 2 novels $) \vee \diamond($ you read exactly 4 novels))

c. $\odot$ you read exactly 4 novels $\rightarrow(\diamond$ (you read exactly 2 novels $) \vee \diamond($ you read exactly 3 novels))

\section{Conclusion}

In this paper, we have presented a novel contrast in the domain of the existential expressions that convey a 'don't know how many' effect: we have shown that at least $n$ contrasts with algún que otro in that only the former conveys a 'lower bound component.' In line with recent literature on epistemic indefinites (see, e.g. Alonso-Ovalle \& Menéndez-Benito 2010 or Fălăuş 2011), we have proposed that this contrast can be derived by assuming that the two items trigger different kinds of pragmatic competitors.

\section{References}

Alonso-Ovalle, Luis \& Paula Menéndez-Benito. 2008. Minimal domain widening. In Natasha Abner \& Jason Bishop (eds.), West Coast Conference on Formal Linguistics (WCCFL), 27, 36-44. Somerville, MA: Cascadilla Proceedings Project.

Alonso-Ovalle, Luis \& Paula Menéndez-Benito. 2010. Modal indefinites. Natural Language Semantics 18(1). 1-31.

Alonso-Ovalle, Luis \& Paula Menéndez-Benito. 2011. Expressing indifference: Spanish Un NP Cualquiera. In Neil Ashton et al. (ed.), Semantics and Linguistics Theory (SALT), 21, 333-347. CLC Publications.

Alonso-Ovalle, Luis \& Paula Menéndez-Benito. 2013. Two views on epistemic indefinites. Language and Linguistics Compass 7(2). 102-122.

Büring, Daniel. 2008. The least at least can do. In Charles B. Chang \& Hannah J. Hayne (eds.), West Coast Conference on Formal Linguistics (WCCFL), 26, 114-20. Cascadilla Press.

Cohen, Ariel \& Manfred Krifka. 2011. Superlative quantifiers as modifiers of meta-speech acts. The Baltic International Yearbook of Cognition, Logic and Communication 6(0). 1-56. doi:10.4148/biyclc.v6i0.1578.

Cummins, Chris \& Napoleon Katsos. 2010. Comparative and superlative quantifiers: Pragmatic effects of comparison type. Journal of Semantics 27. 271-305. von Fintel, Kai. 2000. Singleton indefinites (re. Schwarzschild 2000). Ms., MIT. 
Modal determiners and alternatives

Fălăuş, Anamaria. 2009. Polarity Items and Dependent Indefinites in Romanian: Université de Nantes Ph.D. dissertation.

Fălăuş, Anamaria. 2011. Alternatives as sources of semantic dependency. In Nan Li \& David Lutz (eds.), Semantics and Linguistics Theory (SALT), 20, 406-427. CLC Publications.

Gazdar, Gerald. 1979. Pragmatics: Implicature, Presupposition and Logical Form. New York: Academic Press.

Geurts, Bart \& Rick Nouwen. 2007. At least et al.: The semantics of scalar modifiers. Language 83. 533-559.

Gutiérrez-Rexach, Javier. 2010. Varieties of indefinites in Spanish. Language and Linguistics Compass 4(8). 680-693.

Horn, Laurence. 1989. A Natural History of Negation. Chicago, IL: Chicago University Press.

Kratzer, Angelika. 2003. Indefinites and functional heads: From Japanese to Salish. Talk given at the 13th Semantics and Linguistic Theory Conference, 2003, University of Washington (Seattle).

Kratzer, Angelika. 2005. Indefinites and the operators they depend on: From Japanese to Salish. In Gregory N. Carlson \& Francis Jeffry Pelletier (eds.), Reference and Quantification: The Partee Effect, 113- 142. Stanford: CSLI.

Kratzer, Angelika \& Junko Shimoyama. 2002. Indeterminate pronouns: The view from Japanese. In Y. Otsu (ed.), 3rd Tokyo Conference on Psycholinguistics, 1-25. Hituzi Syobo.

Nilsen, Øystein. 2007. At least free choice and lowest utility. Talk presented at the ESSLI Workshop on Quantifier Modification, Dublin.

Nouwen, Rick. 2010. Two kinds of modified numerals. Semantics and Pragmatics 3(3). 1-41.

Nouwen, Rick. forthcoming. Modified numerals: The epistemic effect. In Luis Alonso-Ovalle \& Paula Menéndez-Benito (eds.), Epistemic Indefinites, Oxford University Press.

Sauerland, Uli. 2004. Scalar implicatures in complex sentences. Linguistics and Philosophy 27(3). 367-391.

Schwarz, Bernhard. 2011. Remarks on class B numeral modifiers. Handout for a talk at the workshop Indefinites and Beyond, University of Göttingen, November 18-19, 2011.

Schwarz, Bernhard. 2013. Ignorance implicature and symmetry. Talk presented at the workshop Exploring the Interfaces 2: Implicatures, Alternatives, and the Semantics/Pragmatics Interface, McGill University, May 22-24.

Zimmerman, Thomas Ede. 2000. Free choice disjunction and epistemic possibility. Natural Language Semantics 8(4). 255-290. 
Alonso-Ovalle and Menéndez-Benito

Luis Alonso-Ovalle

Paula Menéndez-Benito

Department of Linguistics

Seminar für Englische Philologie

Department of Languages, Literatures and Cultures

University of Göttingen

McGill University

Avenue du Docteur Penfield 1085

Käte-Hamburger-Weg 3

37073 Göttingen, Germany

Montréal, Québec, Canada H3A 1A7

pmenend@gwdg.de

luis.alonso-ovalle@mcgill.ca 